\title{
Vein of the Head or Neck
}

National Cancer Institute

\section{Source}

National Cancer Institute. Vein of the Head or Neck. NCI Thesaurus. Code C33856.

Any blood vessel within in the head or neck that transports deoxygenated blood. 